\title{
The Primary Care Practitioner and the diagnosis of occupational diseases
}

\author{
Luca Cegolon*1,2, John H Lange ${ }^{3}$ and Giuseppe Mastrangelo1
}

\begin{abstract}
Background: Rather than a clinical diagnosis, in occupational medicine the critical point is the etiological diagnosis. The first is useful for the therapy, the latter for preventive, epidemiological, regulatory, and insurance measures.

Discussion: As with causality criteria which are employed in population studies, the answering of four easy questions allows a Primary Care Practitioner to establish a causal link between the work activities and a potential disease that a specific patient may present.

After determining the clinical diagnosis and the actual pathology of an occupational disease, the identity, duration, and intensity of the exposure have to be detected for establishing a close-causal effect. The judgment on the occupational origin of the disease requires an integrated approach using multiple sources of information, and goes beyond the clinical diagnosis. This may require consultation with a specialist in occupational medicine.

Summary: It is important that the Primary Care Practitioner takes an accurate medical history since this may be the only chance a patient has to have their occupational disease recognised and properly detected/identified. Proper identification of the causative nature of such diseases is important for establishing preventive measures in eliminating and controlling future cases against exposure, epidemiological reporting and studies (particularly in identifying the rates of disease), regulatory reporting requirements and insurance compensation.
\end{abstract}

\section{Background}

A historical judgment by the Venice Appeal Court (Italy) in 2004 finally put an end to a controversial class-action law suit, which began over 10 years prior, by denouncing the deaths of 120 workers by various types of tumours. These workers had been employed since the 1950s in the chemical plants at Porto Marghera (Italy) and were involved in the production of vinyl chloride (VC) and polyvinyl chloride (PVC). VC and PVC were recognised cancer agents by the International Agency for Research on Cancer (IARC) and the European Economic Area (EEA) since the 1970s and repeated reports, notifications and denouncements about their possible role in the health problems of several workers in the 70s and $80 \mathrm{~s}$ at Porto Marghera fell on deaf ears and were disregarded. Despite the occupational situation at these industrial plants being defined as "alarming" by some experts since 1977, governmental insurance companies were not will-

*Correspondence: I.cegolon@gmail.com

1 Padua University, Department of Environmental Medicine and Public Health, Padua, Italy

Full list of author information is available at the end of the article ing to recognise the potential occupational nature of the health problems affecting the blue-collar workers, thus continuously denying them compensation. On 22 August 1994 the prosecuting attorney decided to intervene and began by investigating the real occupational mortality and disease rates of the workers involved in the management of $\mathrm{VC}$ and $\mathrm{PCV}$, as data provided thus far by the industrial companies, underestimating the phenomenon, were not convincing [1]. On the assumption that the results of any consultations undertaken by occupational doctors employed by the industrial companies at this time were probably biased, the most reliable and effective health care resource available to these workers would have probably been their Primary Care Practitioner (PCP).

In occupational medicine the critical point is not clinical diagnosis (e.g. rhinitis), but instead the etiological diagnosis (e.g. rhinitis caused by anhydrides). The first diagnosis is useful for therapy while the latter is utilised for preventive, epidemiological, regulatory and insurance measures. 
It has been reported that PCPs continue to do a poor job of obtaining an occupational history and it has been identified that additional medical education is needed to correct these inadequate practices $[2,3]$. These issues are of particular importance since PCPs are often the first to see patients with occupational diseases [4]. This makes their findings of critical importance since they will often make the initial determination and sometimes undertake the only evaluation as to whether the patient's condition is a result of an occupational event.

\section{Discussion}

\section{Setting up an hypothesis of work}

To detect an occupational disease it is necessary to investigate some aspects which are often neglected by solely taking the patient's medical history. The clinical history could be supplemented by employing some questions which rely on some of the criteria for cause-effect relationship normally used in occupational epidemiology population studies [5]. The answering of only four easy questions could be sufficient for a PCP to suspect a causal link between the work activities and the disease of a specific patient [3,6].

The suspicion of an occupational disease is reasonable when the cause precedes the effect of an interval sufficient for the development of the pathological process (query 1 ) and one or more positive answers are obtained from the queries 2-4 of table 1[5-7].

\section{Expounding upon the information collected}

It is necessary to define with clinical diagnosis the actual pathology of a disease along with the identity, duration and intensity of the exposure agent. This can be elucidated by identifying a specific chemical substance, physical, biological or psychological risk factor for that patient

\section{Table 1: The four questions giving rise to suspicion of the occupational nature of a disease.}

HISTORY TAKING IN OCCUPATIONAL MEDICINE

Criteria for causal Queries to be addressed to the patient
relationship in
epidemiology

Temporal

relationship

Dose-effect

relationship
1. What is the time lag between the initial exposure and the start of the symptoms?

2. Do the symptoms improve if the patient is not exposed any longer (e.g. if he/she changes work duties or is on holiday?

3. Do the symptoms worsen if the patient carries out specific duties or works in areas characterised by high levels of exposure?

Strength of the association
4. Are colleagues affected by the same symptoms related to the same exposure?
[8-10]. A simple inquiry about the work duties of the patient does not provide adequate information and in some cases this alone may be misinterpreted by the PCP [11].

Establishing the existence of an occupational disease often requires the examination of:

1 Evidence from epidemiological studies where the disease in question is recognised as caused by the same exposure agent (substance);

2 Chemical data sheets, reporting the chemical substances contained in each product; in particular information such as "risk sentences", describing the types of symptoms potentially caused by the substance; 3 List of occupational diseases related to that specific industry or agricultural activity/practice;

4 List of mandatory notifiable diseases.

In the case of occupational diseases the physician must [12-14]:

1 Notify the occurrence of this disease case to the legal/regulatory authorities, if there is any legal responsibility for such notification;

2 Notify the occurrence of the occupational disease case to the public health authorities (if it is mandatorily notifiable);

3 Certify the occupational disease so the patient can file/claim compensation from the government/insurance companies for this disease state.

\section{Problems and solutions}

Determining the duration of the exposure can be difficult and in some cases frustrating (particularly if there have been repeated periods of exposure and the patient has moved in and out of exposure scenarios), but should not cause great difficulty for the physician [6]. Simply identifying the type or types of exposure that the patient has from their employment can be accomplished through use of common occupational medicine/toxicological/industrial hygiene textbooks [15-17]. By contrast, deriving the intensity of exposure from the patients' employment history can be far more complicated $[6,18]$. However, the simple answer is that if the worker used/uses Personal Protection Equipment (PPE) (masks/respirators, gloves, etc.) this may be sufficient to provide a basic answer that exposure is likely to be occurring; although, may not provide sufficient information as to whether the PPE is sufficiently protective. In fact there are different forms of PPE and each has varying value in providing protection against harmful agents [6,19-21]. For instance, gloves protect against solvents and other toxicants only if chosen with the awareness of the type of materials suitable in each case[19].

To fully understand potential exposure, it is sometimes necessary to obtain the complete occupational history of the patient, occasionally going back several decades, as 
illustrated with the diseases mesothelioma and liver angiosarconoma. These diseases can occur up to 40 years since the exposure to asbestos [22] and vinyl chloride (VC) [23] respectively. This will assist the PCP in assessing the workplace exposure, preventing misunderstandings of practices and activities in the workplace and their over-reliance on descriptive information provided by the patient [11].

Finally, the judgment on the occupational origin of the disease can require an integrated approach using multiple sources of information. For instance, the presentation of cough and dyspnoea in a worker who smokes does not necessarily signify that the symptoms are solely attributable to smoking [24].

The guidelines hereby mentioned should be used as a preliminary tool. For further investigation on the potential occupational nature of a disease physicians should subsequently refer to the online database of the National Library of Medicine's Toxicology and Environmental Health Information Program (TEHIP). TEHIP is a relevant portal reporting extensive toxicological information worldwide, including several scientifically peer-reviewed databases residing within the web-based TOXNET system [25]. Haz-Map is one of these occupational toxicology databases available on the National Library of Medicine's TOXNET system. Haz-Map is designed primarily for health and safety professionals, but also for consumers seeking information about the health effects of exposure to chemicals and biological compounds at work. It links jobs and hazardous tasks with occupational diseases and their symptoms. The 1,595 chemicals and biological agents in the database are related to industrial processes and other activities such as hobbies. The linkage indicates the potential for exposure to the agents. The 224 occupational diseases and their symptoms are associated with hazardous job tasks. This association indicates an increased risk for significant exposure and subsequent disease [26]

As the clinical diagnosis of the disease may require appropriate tests (laboratory tests, diagnostic imaging) the etiological diagnosis may need consultation from a specialist in occupational medicine for adequate confirmation.

Lastly it is important for the PCP to be vigilant and aware that patients/workers might also be reluctant to disclose information on their potential occupational exposure because of the repercussions this may have on other people and their employer.

\section{Summary}

The taking of an accurate and complete history by the PCP may sometimes be the only chance a patient has to have the occupational nature of his/her disease detected $[4,27]$. Failure in this respect can result in the patient not being listed in the appropriate registry for the relevant disease, the patient being denied insurance/governmental benefits and furthermore, the opportunity to take preventative measures in an attempt to eliminate future cases in other workers may be missed $[28,29]$.

Taken together, these factors will prevent the case from being included in epidemiological data, thus resulting in an underestimation or miscount of the true number of cases of a specific occupational disease [30].

A simple guide, as presented here, will assist PCPs overcome any of their inadequacies in occupational medicine, especially related to their understanding of the workplace environment [11], with the ultimate aim being to achieve a higher rate of preventable disease along with a mechanism for reducing occupational compensation for these diseases [22]. It will also allow physicians to gain a better understanding of occupational events and workplace illnesses through self-education involving case-bycase evaluation of occupational diseases. In addition we hope that by educating PCPs in this way their failure rate in detecting occupational disease will be reduced and thereby increase the surveillance of specific diseases by a resultant increase in the reporting by PCPs to regulatory agencies and, in part, to the epidemiological literature [30].

For these reasons it is crucial that the PCP be alert and aware of the complexities involved in this type of diagnosis and thoroughly investigates and pursues all avenues of inquiry into the disease(s) of their patients. Overall, PCPs are often the gatekeepers for detection, diagnosis and treatment of occupationally related diseases, which places them in a unique position to provide adequate care to these patients [4] along with obtaining occupational compensation for the injured worker [11]. Inadequate evaluation will only hinder the future prevention and proper identification and reporting of occupational diseases. Undertaking comprehensive evaluations into the patient's disease can have a dramatic impact on the patient's total health and well-being and result in improved quality of life [22].

\section{Abbreviations}

VC: Vinyl Chloride; PVC: Polyvinyl Chloride; PCP: Primary Care Practitioner; IARC: International Agency for Research on Cancer; EEA: European Economic Area; PPE: Personal Protection Equipment; TEHIP: Toxicology and Environmental Health Information Program.

\section{Competing interests}

The authors declare that they have no competing interests.

\section{Authors' contributions}

LC conceived the idea and developed the paper. JHL contributed in the drafting of the paper. GM conceived the idea and is the guarantor. All authors read and approved the final manuscript

\section{Acknowledgements}

We thank Ms. Daisy Alice Dunger for her advice in the drafting of the manuscript and Gianluca Marangi for his suggestions in the initial stages of the paper. 


\section{Author Details}

Padua University, Department of Environmental Medicine and Public Health Padua, Italy, ${ }^{2}$ Imperial College London, School of Public Health, St Mary's Campus, Norfolk Place, London, UK and 'Envirosafe Training and Consultants, Pittsburgh, Pennsylvania, USA

Received: 5 April 2010 Accepted: 9 July 2010

Published: 9 July 2010

\section{References}

1. Processo: Petrolchimico. Italy [http://www.petrolchimico.it]. (accessed on 29 June 2010)

2. Politi BJ, Arena VC, Schwerha J, Sussman N: Occupational Medical History Taking: How Are Today's Physicians Doing? A Cross-Sectional Investigation of the Frequency of Occupational History Taking by Physicians in a Major U.S. Teaching Center. Journal of Occupational and Environmental Medicine 2004, 46:550-555.

3. Newman LS: Occupational Illness. New England Journal of Medicine 1995, 333:1126-1134

4. Lee J, Liem LP, Koh d: Occupational health in general practice in an industrial area of Singapore. Occupational Medicine 2001, 51:312-317.

5. Hill AB: The environment and disease: association or causation? Proc $R$ Med Soc 1965, 58:295-300

6. Agius R: Taking an Occupational History. Health Environment \& Work 2000 [http://www.agius.com/hew/resource/occhist.htm]. (updated in April 2010; accessed on 21 June 2010)

7. Lax MB, Grant WD, Manetti FA, Klein R: Recognizing Occupational Disease - Taking an Effective Occupational History. American Academy of Family Physicians 1998 [http://www.aafp.org/afp/980915ap/lax.html]. (accessed on 30th June 2010)

8. Kivimaki M, Ferrie JE, Hagberg J, Head J, Westerlund H, Vahtera J, Alexanderson K: Diagnosis-specific sick leave as a risk marker for disability pension in a Swedish population. Journal of Epidemiology and Community Health 2007, 61:915-20.

9. Boersma K, Linton SJ: Screening to identify patients at risk: profiles of psychological risk factors for early intervention. Clin J Pain 2005, 21:38-43.

10. Vandenplas O, Ghezzo H, Munoz X, Moscato G, Perfetti L, Lemiere C, Labrecque M, L'Archeveque J, Malo JL: What are the questionnaire items most useful in identifying subjects with occupational asthma? European Respiratory Journal 2005, 26:1056-63.

11. Russell G, Brown JB, Stewart M: Managing injured workers: family practice experiences. Canadian Family Physician 2005, 51:78-79.

12. WHO: Guidelines on quality Managements in Multidisciplinary Occupational Health Services. 1999 [http://www.who.int/ occupational health/regions/en/oeheurqualitymanagement.pdf]. Bilthoven: WHO European Centre for Environment and Health accessed on 16 July 2010

13. European Agency for Safety and Health at Work: Dangerous substances. Handle with care. Magazine 6 of the European Agency for Safety and Health at Work. 2003 [http://osha.europa.eu/en/publications/magazine/6]. (Accessed on 16 July 2010)

14. Public Health Act 2008: 2008 Legislative Session: 4th Session, 38th Parliament [http://www.leg.bc.ca/38th4th/3rd read/gov23-3.htm]. (accessed on 30th June 2010)

15. Wolters Kluwer/Lippincott Williams \& Wilkins, 2007, Hathaway GJ, Proctor $\mathrm{NH}$, Hughes JP, Fischman ML: Proctor and Hughes' Chemical hazards of the workplace. Van Nostrand Reinhold, New York; 1991.

16. Klaassen CD: Casarett and Doull's Toxicology: The Basic Science of Poisons. 7th edition. McGraw-Hill Publishers, New York, NY; 2008

17. Rom WN, Markowitz S: Environmental and occupational medicine. 4th edition. Wolters Kluwer/Lippincott Williams and Sons, Philadelphia; 2007.

18. Mastrangelo G, Scoizzato L, Ballarin MN, Bellini E, Bizzotto R, Zannol F, Gioffre F, Gobbi M, Tessadri G, Marchioni L, Valentini F, Marangi G, Lange $\mathrm{JH}$ : Smoking habits, exposure to asbestos, asbestosis and pleural plaques in 772 past asbestos workers examined by computed tomography. American Journal of Industrial Medicine 2009, 52:596-602.

19. LaDou J: Current Occupational and Environmental Medicine. 4th edition. McGraw-Hill Publishers, New York, NY; 2008

20. Health and Safety Executive (HSE): COSHH Essentials--easy steps to control chemicals (HSG 193). Sudbury: HSE Books; 1999. ISBN 07176 2421
21. Garrod ANI, Rajan Sithamparanadarajah R: Developing COSHH Essentials: Dermal Exposure, Personal Protective Equipment and First Aid. Ann Occup Hyg 2003, 47:577-588.

22. Mowe G, Gylseth B, Hartveit F, Skaug V: Occupational asbestos exposure, lung-fiber concentration and latency time in malignant mesothelioma. Scand J Work Environ Health 1984, 10:293-298.

23. CDC: Vynil Chloride (p. 18). [http://www.atsdr.cdc.gov/toxprofiles/tp20c2.pdf]. (accessed on 30 June 2010)

24. Rosenstock L, Cullen MR: Clinical Occupational Medicine. WB Saunders Company, Philadelphia PA; 1986.

25. Wexler P: The US National Library of Medicine Toxicology and Environmental Health Information Program. Toxicology 2004, 198:161-168.

26. Fitzpatrick RB: Haz-Map: information on hazardous chemicals and occupational diseases. Medical Reference Services Quarterly 2004, 23(2):49-56.

27. AJ , Anema JR, van der Wal G, van Mechelen W: Work-related disease in general practice: a systematic review. Family Practice 2005, 22:197-204.

28. Driscoll TR, Hendrie AL: Surveillance of work-related disorders in Australia using general practitioner data. Australian New Zeland Journal of Public Health 2002, 26:346-51.

29. Won JU, Dembe AE: Services provided by family physicians for patients with occupational injuries and illnesses. Annals of Family Medicine 2006, 4:138-47.

30. Oleinick A, Zaidman B: The law and incomplete database information as confounders in epidemiologic research on occupational injuries and illnesses. American Journal of Industrial Medicine 2010, 53:23-36.

\section{Pre-publication history}

The pre-publication history for this paper can be accessed here: http://www.biomedcentral.com/1471-2458/10/405/prepub

doi: $10.1186 / 1471-2458-10-405$

Cite this article as: Cegolon et al., The primary care practitioner and the diagnosis of occupational diseases BMC Public Health 2010, 10:405

\section{Submit your next manuscript to BioMed Central and take full advantage of:}

- Convenient online submission

- Thorough peer review

- No space constraints or color figure charges

- Immediate publication on acceptance

- Inclusion in PubMed, CAS, Scopus and Google Scholar

- Research which is freely available for redistribution 